\section{Big-Five Personality Profile of Executive Search Recruiters}

\section{Cass Dykeman ${ }^{1}$ and James J. Dykeman}

A Preprint. The copy of record can be found at https://doi.org/10.1002/j.21611920.1996.tb00438.x

\begin{abstract}
This study surveyed a sample of nationally certified executive search recruiters, with the use of the NEO Five-Factor Inventory (NEO-FFI). Chi-square test analyses revealed that this sample differed significantly from adult norms on 4 of the 5 NEOFFI scales. These scales were Neuroticism, Extraversion. Openness. and Conscientiousness. Implications of these findings for employment counselor practice are discussed.
\end{abstract}

\section{Introduction}

Executive search professionals act as major players in personnel acquisition worldwide. In the United States, executive search recruiting is a $\$ 41.6$ billion a year industry (Hawkinson, 1994). Despite the influence of this profession on the American business community, no examination of executive search recruiter (ESR) psychological variables has appeared in the professional literature. This study aims to fill that gap. Knowledge of such variables can help employment counselors as they work with clients who are using an ESR or with clients who are considering executive search recruiting as a profession. ESRs work both on a retainer and on a contingency basis. Executive search recruiting work settings generally demand a high degree of employee autonomy. This type of recruiting involves generating both job orders and candidates. Typically, potential candidates are employed already and not actively seeking another position. Nevertheless, most potential candidates are open to hearing about opportunities that would result in the advancement of their pay, power, or prestige. Almost $100 \%$ of executive search recruiting occurs by telephone. This work includes a great deal of "cold calling, a term that refers to unsolicited telephone calls aimed at either candidates or companies.

There are two different types of cold callingSpin-of-the-Dial (SOD) calling and Search calling. SOD calling is a situation in which the ESR hopes to obtain a job order from a company and then searches to find a candidate to fill that position. Search calling is a situation in which the ESR seeks strong candidates and then markets these candidates to companies. In the case of search calling, the companies contacted may or may not currently have a position open. The ESR's goal in search calling is to convince a company that their candidate is so strong that it would be unwise not to create a position for the candidate. The typical ESR makes 125 cold calls each day. On average, only four of these calls result in either a job order or a candidate.

The histories of business and psychology have been intertwined since the beginning of modern scientific psychology. One psychological variable particularly salient to personnel issues is personality. For instance, Holland's influential theory of career development held the idea that personality is a prime determiner of both career selection and success (Costa, McCrae, \& Holland, 1984; Holland, 1959). Yet, the overall research record of personality as a predictor variable in career issues is mixed. Early empirical investigations using personality failed to find this psychological variable a useful predictor of occupational success (Guion \& Gottier, 1965). More recent researchers in this area have attributed this failure to the lack of a well-accepted personality taxonomy (Barrick \& Mount, 1991; Schroeder, Broach, \& Young, 1993). Barrick and Mount (1991) argued that it is impossible to uncover consistent relationships between personality and performance without such a taxonomy.

1. Correspondence concerning this article should be addressed to Cass Dykeman, Counseling Academic Unit, Oregon State University, dykemanc@oregonstate.edu 
In personality research, this taxonomic uncertainty has eased in the past few years. There has been a growing convergence in personality research toward one model. This convergence centers on the Big-Five model of personality (Barrick \& Mount, 1991). Recent empirical research has demonstrated the utility of this model with various career development questions (Barrick \& Mount, 1991, 1993; Hough, Eaton, Dunnette, Kamp, \& McCloy, 1990; Schroeder et al., 1993; Tokar, Vaux, \& Swanson, 1995). Barrick and Mount (1993) found the relationship between personality variables and career issues even stronger for work demanding a high degree of employee autonomy. Executive search recruiting demands the ability to work with a high degree of autonomy.

The Big-Five model has five basic dimensions. These dimensions represent second-order factors drawn from empirical analysis of previous quantitative personality research (Reader's note. See Dig- man, 1989, 1990, for excellent literature reviews on the nature and development of this model). Big-Five personality dimensions include (a) neuroticism, (b) extraversion, (c) openness, (d) agreeableness, and (e) conscientiousness. Miller (1991) and McCrae and Costa (1991) included detailed phenomenological descriptions of these dimensions in their articles.

The Big-Five model offers some unique characteristics that favor its use in a study of ESRs. First, this model is comprehensive. The five dimensions in this model account for a majority of personality variance and thus give a full picture of the group under study (McCrae \& Costa, 1987). Second, this model is a trait model. As a result, the five traits in this model are stable over time (Costa \& McCrae, 1988). Moreover, these dimensions have an impact on behaviors that are highly relevant to executive search recruiting work. These behaviors include (a) reactions to stress, (b) occupational interests, (c) creativity, and (d) interpersonal relations (McCrae \& Costa, 1991). Third, the BigFive model is a model of normal rather than pathological personality traits (McCrae \& Costa,
1991). This characteristic is particularly critical when the group under study is not a clinical population.

Given the aforementioned strengths of the BigFive model, research using this model can explicate the personological elements of the executive search recruiting work environment. Knowledge from such research is a critical prerequisite to employment counseling. Under- standing the personological characteristics of a profession can help an employment counselor and a client better discern if that profession would represent a good personenvironment fit for the client. Determination of a good fit leads to the best employment counseling outcomes (Holland, 1985; Meir, 1989; Spokane, 1985, 1991).

ESRs play an important role in American industry; yet, as stated earlier, there has been no psychological study of this population. Thus, we sought to collect empirical data on a psychological variable known to influence both career selection and success-personality. As previously discussed, executive search recruiting involves both sales and marketing work. Previous personality research on marketing and sales personnel has suggested that ESRs are more extraverted than the general adult population (Bendig, 1963; Costa, Fozard, \& McCrae, 1977; Hansen \& Campbell, 1985; Johansson, 1970; Johnson, Flammer, \& Nelson, 1975). Still, there is no consensus on the exact strength of the relationship between these two vocational areas and extraversion (Morris, 1979: Turnbull, 1976). In terms of the other four dimensions, no directional hypotheses could be culled from a review of the personality research literature. Thus, it remains unclear how, if at all, ESRs differ from the general adult population in these dimensions.

Given the gaps in the literature on the personality characteristics of ESRs, we sought to conduct an empirical exploration of this important profession in the area of personnel acquisition. The specific objectives of this study were (a) to 
determine if ESRs are more extraverted than the general adult population as suggested by research on related professions: (b) to discover if ESRs differ from the general adult population in reference to the personality dimensions of neuroticism. openness, agreeableness, and conscientiousness; and (c) to develop recommendations for employment counselor practice.

\section{Method}

\section{Participants}

The participants were 114 ESRs attending a national continuing education conference. A major executive search recruiting corporation sponsored this conference and all who attended worked for one of the corporation's franchises. All participants were experienced ESRs who possessed a national certification. The mean ESR age was $44.73(S D=$ 8.80). The mean number of years employed as an ESR was $8.52(S D=3.85)$. ESR respondents were predominately men (58\%). The percentage of participants that possessed a baccalaureate degree or higher stood at 54. The means for 1992, 1993, and career ESR earnings were $\$ 158,279(S D$ $=\$ 100,849), \$ 180,453 \quad(S D=\$ 119,867)$, and $\$ 1,058,868(S D=\$ 630,716)$, respectively.

\section{Measures}

Personality. The Big-Five personality dimensions were measured by the NEO Five-Factor Inventory (NEO-FFI. Costa \& McCrae, 1992). The NEO- FFI is a short form of the NEO PI. Costa and McCrae created this 60-item inventory from their extensive factor analytic studies on personality using the NEO PI. (Reader's note. See Costa and McCrae, 1988, for a review of this work.) The NEOFFI manual details the research supporting the content and construct validity of the instrument (Costa \& McCrae, 1992). The NEO-FFI contains 5 scales of 12 items, each corresponding to the five dimensions of this personality model. The scales are (a) Neuroticism, (b) Extraversion, (c) Openness, (d) Agreeableness, and (e) Conscientiousness.
In the NEO-FFI manual, Costa and McCrae (1992) reported that when the NEO-FFI was correlated with the NEO PI-R domain scales, the correlations discovered were Neuroticism, .92; Extraversion, .90: Openness, .91; Agreeableness, .77; and Conscientiousness, .87. In this manual Costa and McCrae also provided the following alpha coefficients for the NEO-FFI scales: Neuroticism, .86; Extraversion, .77; Openness, .73; Agreeableness, .68; and Conscientiousness, .81. Other personality researchers using the NEO- FFI have noted finding acceptable reliability coefficients for the five scales (Borkenau \& Ostendorf, 1991; Schmit \& Ryan, 1993; Yeung. Lyons, Waternaux, Faraone, \& Tsuang, 1993).

Demographics. In addition to the NEO-FFI, the packet distributed to all conference attendees contained a questionnaire requesting information on age, sex, education, and executive search recruiting experience. This questionnaire also requested data on 1992, 1993, and career ESR earnings.

\section{Procedure}

All 114 ESRs attending a national continuing education conference received a packet containing the measures used in this study. The packets were part of the registration materials distributed at the start of the conference. Besides containing the measures, these packets also had an introduction letter, which gave detailed information on how to complete the materials in the packet. Also, this letter instructed the ESRs to complete the packet material anonymously and return it before the close of the conference. Of the ESRs, 59 (52\%) returned the packet. Because of missing data, 11 of these packets were unusable. Thus, 48 packets were available for analyses.

\section{Results}

We converted NEO-FFI raw scale scores to $\mathrm{T}$ scores using the adult norms (Costa \& McCrae, 1992). Figure 1 displays the ESRs' Big-Five 
personality profile using these $\mathrm{T}$ scores. These scores also served as the basis for the placement of individual ESR results into the appropriate interpretative category for each scale.

Costa and McCrae (1992) recommended the conversion of respondents' $\mathrm{T}$ scores into preset interpretative categories. In the NEO- FFI manual, they provided three interpretative categories per scale and supplied descriptors of persons falling into each category. These categories were high ( $\mathrm{T}$ scores of 56 and above), average ( $\mathrm{T}$ scores of 55 to 45). and low (T scores of 44 and below). One sample chisquare test analyses was conducted to discover whether the ESRs' interpretative category frequencies differed from expected frequencies based on national norms (Siegel \& Castellan, 1988). An alpha level of .01 was set for all analyses. Table 1 shows the results from the analyses. Overall. ESRs differed from the adult norm group on all but the Agreeableness scale.

\section{Discussion}

The aim of this study was to generate empirical data on how ESRs may differ from the general adult population in reference to personality. Statistical analyses found that ESRs differed significantly in four of the five dimensions of the Big-Five model. On the Neuroticism scale, almost twice as many ESRs as were expected fell into the low range category. Also, ESRs in the high range were slightly more than a quarter of the number expected. Thus, as a whole, the veteran ESRs that participated in this study were more emotionally stable than the adults were in the norm group.

The results from the Extraversion and Openness scales were similar. Greater than expected frequencies occurred in the high range category. In the case of the Extraversion scale, the high range frequency exceeded twice as many ESRs as expected. This high extraversion rate was consistent with the results of personality research on occupations related to executive search recruiting. With both the Extraversion and Openness scales, the observed cases in the low range were a third or less the number expected. Thus, overall, the ESRs were more extraverted and open to experience than the adult norm group was.

The results from the analysis of the Conscientiousness dimension differed from all other analyses. More than one and a half times the expected number of ESRs fell into the average range. Approximately one quarter of the number expected in low range ESRs appeared in this category. Therefore, with the Conscientiousness scale, there was a strong skew toward an average or higher categorization.

Given the research findings previously noted, a general ESR profile can be constructed using modal NEO-FFI interpretative categories and Costa and McCrae's (1992) descriptors. As a group, veteran ESRs can be described as (a) secure, hardy, and generally relaxed even under stressful conditions; (b) extraverted, outgoing, active, and high spirited; (c) open to new experiences; and (d) dependable and moderately well organized.

The results of this study can help employment counselors improve their services to clients in two ways. First, employment counselors can use the findings of this study to increase their knowledge of the executive search recruiting profession. Although this profession is growing and can be highly lucrative, it is not well understood in the counseling community. With greater understanding of executive search recruiting, employment counselors can better discuss with clients the opportunities associated with this profession. Also, an increased knowledge of executive search recruiting work can help employment counselors to better advise clients who are considering the use of ESRs.

The second benefit of this study's findings concerns person- environment fit issues with clients who are considering executive search recruiting as a career. Awareness of the ESR personality profile that this study produced can help employment counselors determine how well a particular client's personality characteristics mesh with the executive 
search recruiting profession's personological and environmental demands. Following Holland's (1985) widely accepted theory, a good fit increases a client's chances for career success and satisfaction. A client's avoidance of a poor fit can save time, money, and energy for both employer and employee (Bertrand, 1990; Sager, 1991).

This article presented an empirically derived, comprehensive personality profile of veteran ESRs. The ESR personality profile differed significantly from the adult norm group. The population used in this study was restricted to ESRs employed by the franchises of a single executive search recruiting corporation. Also, the following factors could have influenced the results of this study: (a) small sample size, (b) modest return rate, and (c) the fact that the sample was drawn from ESRs attending a continuing education event. Therefore, the findings of this research project may not apply to other ESR samples. Replication of this project would be a welcomed addition to the study of this globally influential profession.

\section{References}

Barrick, M. R., \& Mount, M. E. (1991). The Big Five personality dimensions and job performance: A meta-analysis. Personnel Psychology, 44, 1-26.

Barrick. M. R., \& Mount, M. K. (1993). Autonomy as a moderator of the relationship between the Big Five personality dimensions and job performance. Journal of Applied Psychology, 78, 111-118.

Bendig. A W. (1963). The relationship of temperament traits of social extraversion and emotionality to vocational interests. Journal of General Psychology , 69, 311-318.

Bertrand, K. (1990). Hiring tests: Sales managers' dream or nightmare? Business Marketing, 75, $34-42$.

Borkenau. P.. \& Ostendorf, F. (1991). Ein fragebogen zur erfassung funf roobuster personlichketrsfactoren (A questionnaire for assessing five robust personality factors).

Diagnostica, 37, 29-41.

Costa, P. T.. \& McCrae. R. R. (1988). Personality in adulthood: A six-year longitudinal study of self-reports and spouse ratings on the NEO Personality Inventory. Journal of Personality and Social Psychology, 54, 853-863.

Costa. P. T.. \& MCrae, R. R. (1992). Professional manual: Revised NEO Personality Inventory and NEO Five-Factor Inventory. Odessa, FL: Psychological Assessment Resources.

Costa. P. T.. Fozard, J. L.. \& McCrae. R. R. (1977). Personological interpretation of factors from the Strong Vocational Interest Blank scales. Journal of Vocational Behavior, 10, 231243.

Costa, P. T.. McCrae. R. R.. \& Holland. J. L. (1984). Personality and vocational interests in an adult sample. Journal of Applied

Psychology, 69, 39400.

Digman, J. M. (1989). Five robust trait dimensions: Development. stability, and utility. Journal of Personality, 57, 195-214.

Digman. J. M. (1990). Personality structure: Emergence of the Five-Factor model. Annual Review of Psychology, 41, 417-440.

Guion, R. M., \& Gottler, R. F. (1965). Validity of personality measures in personnel selection. Personnel Psychology, 18, 135-164.

Hansen, J. C., \& Campbell, D. C. (1985). Strong Interest Inventory manual. Palo Alto, CA: Consulting Psychologists Press.

Hawkinson, P. (1994, July). Myths and other fuzzy thoughts. The Fordyce Letter, 7, 4-10.

Holland, J. L. (1959). A theory of vocational choice. Journal of Counseling Psychology, 6, 35-45.

Holland, J. L. (1985). Making oocation.al choices: $A$ theory of occupational personalities and work environments. Englewood Cliffs. NJ: Prentice Hall.

Hough, L. M., Eaton, N. K., Dunnette, M. D. Kamp. J. D.. \& McCloy, R. A (1990). Criterion-related validities of personality constructs and the effect of response distortion on those validities. Journal of Applied Psychology, 75, 581-595. 
Johansson, C. B. (1970). Strong Vocational Interest Blank introversion-extraversion and occupational membership. Journal of Counseling Psychology, 17, 451-455.

Johnson, R. W., Flammer, D. P.. \& Nelson. J. G. (1975). Multiple correlations between personality factors and the SVIB occupational scales. Journal of Counseling Psychology, 22, 217-223.

McCrae, R. R., \& Costa. P. T. (1987). Validation of the Five-Factor model of personality across instruments and observers. Journal of Personality and Social Psychology. 52, 81-90.

McCrae. R. R., \& Costa. P. T. (1991). The NEO Personality Inventory: Using the Five- Factor model in counseling. Journal of Counseling \& Development, 69, 367-372.

Meir, E. I. (1989). Integrative elaboration of the congruence theory. Journal of Vocational Behavior, 35, 219-230.

Miller, T. R. (1991). The psychotherapeutic utility of the Five-Factor model of personality: A clinician's experience. Journal of Personality Assessment, 57, 415-433.

Morris, L. W. (1979). Extraversion and introversion. Washington, DC: Hemisphere.

Sager, J. K. (1991). Recruiting and retaining committed salespeople. Industrial Marketing Management, 20, 99-103.

Schmit, M. J., \& Ryan, A M. (1993). The Big Five in personnel selection: Factor structure in applicant and nonapplicant populations. Journal of Applied Psychology, 78, 966-974.

Schroeder. D. J., Broach. D.. \& Young. W. C. (1993). Contributions of personality measures to predicting success of trainees In the air traffic control specialist nonradar screen program (DOT/FAA/AM Publication No. 93/4). Oklahoma City. OK: Federal Aviation Administration.

Siegel, S..\& Castellan. N. J. (1988). Nonparametric statistics for the behavioral sciences. New York: McGraw-Hill.

Spokane, A R. (1985). A review of research on person-environment congruence in Holland's theory of careers (Monograph]. Journal of Vocational Behavior, 26, 306-343.

Spokane, A R. (1991). Career intervention. Englewood Cliffs. NJ: Prentice Hall.

Tokar, D. M.. Vaux. A.. \& Swanson, J. L. (1995). Dimensions relating Holland's vocational personality typology and the five-factor model. Journal of Career Assessment, 3, 57-74.

Turnbull. A. A. ( 1976). Selling and the salesman: Prediction of success and personality change. Psychological Reports, 38, 1175-1180.

Yeung, A. S., Lyons. M. J., Waternaux, C. M., Faraone. S. V., \& Tsuang. M. T. (1993). A family study of self-reported personality traits and DSM-III-R personality disorders. Psychiatry Research, 48, 243-255. 
Table 1

Observed and Expected Interpretative Range Frequencies by Factor

\begin{tabular}{|c|c|c|c|}
\hline Group & Observed & Expected & $\chi^{2}$ \\
\hline \multicolumn{4}{|l|}{ Neuroticism } \\
\hline Low & 26 & 14.88 & \\
\hline Average & 18 & 18.24 & \\
\hline High & 4 & 14.88 & $16.26^{* * *}$ \\
\hline \multicolumn{4}{|l|}{ Extraversion } \\
\hline Low & 4 & 14.88 & \\
\hline Average & 11 & 18.24 & \\
\hline High & 33 & 14.88 & $32.89 * * *$ \\
\hline \multicolumn{4}{|l|}{ Openness } \\
\hline Low & 5 & 14.88 & \\
\hline Average & 19 & 18.24 & \\
\hline High & 24 & 14.88 & $12.18^{* *}$ \\
\hline \multicolumn{4}{|c|}{ Agreeableness } \\
\hline Low & 16 & 14.88 & \\
\hline Average & 19 & 18.24 & \\
\hline High & 13 & 14.88 & 0.35 \\
\hline \multicolumn{4}{|c|}{ Conscientiousness } \\
\hline Low & 4 & 14.88 & \\
\hline Average & 31 & 18.24 & \\
\hline High & 13 & 14.88 & $17.11^{* * *}$ \\
\hline
\end{tabular}

1. Correspondence concerning this article should be addressed to Cass Dykeman, Counseling Academic Unit, Oregon State University, dykemanc@oregonstate.edu 


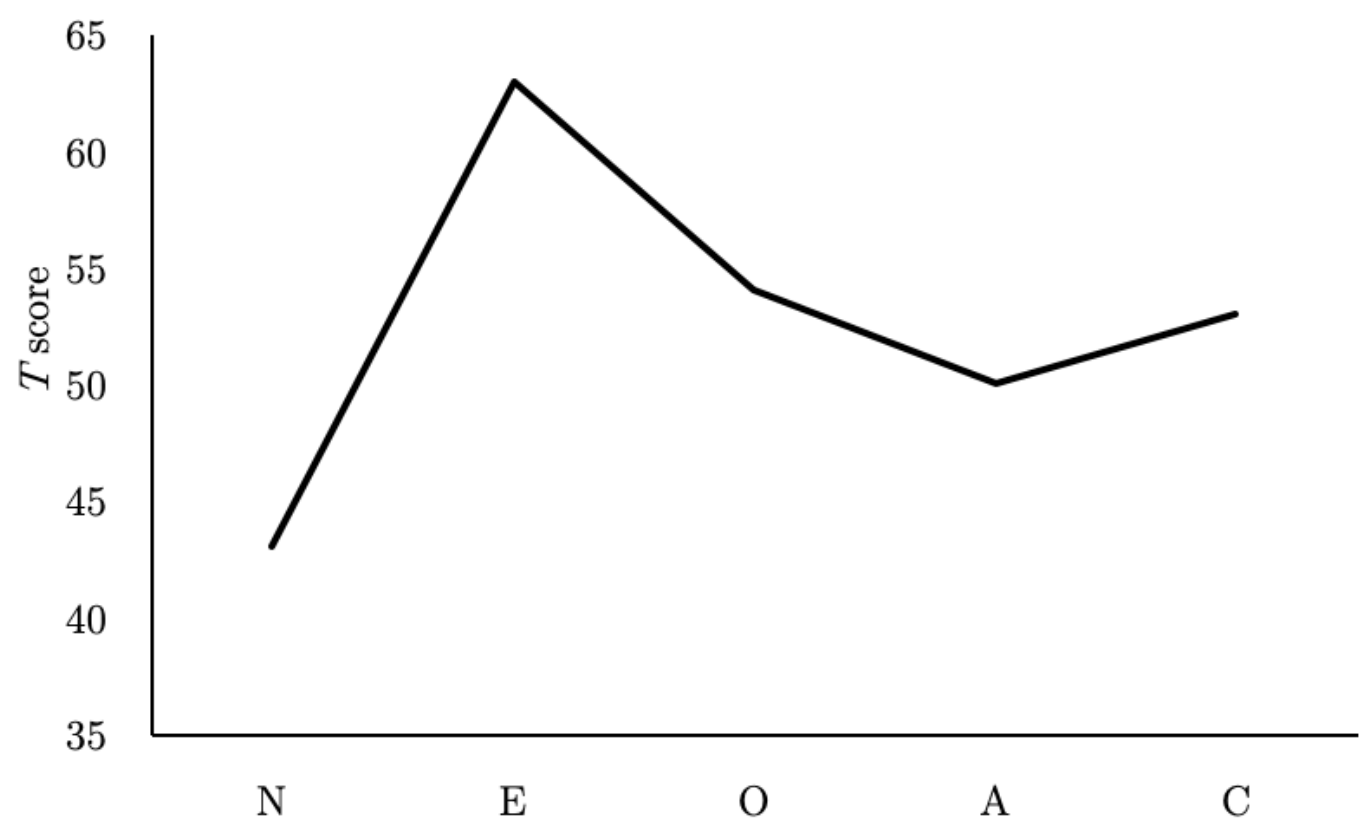

Figure 1. Mean Neo-FFI Factor T Scores of Executive Search Recruiters 